\title{
Uma leitura não-tradicional de Johann Friedrich Herbart: autogoverno pedagógico e posição ativa do educando
}

Claudio A. Dalbosco ${ }^{1}$

\section{Resumo}

0 ensaio trata da obra Pedagogia geral, publicada pelo pedagogo alemão Johann Friedrich Herbart, em 1806. Embora tenha influenciado autores como John Dewey e Jean Piaget, Herbart é tomado até hoje como defensor da pedagogia tradicional, focada nos conteúdos e no papel diretivo autoritário do educador. Visando a desmistificar essa ideia, o ensaio expõe brevemente a arquitetônica da Pedagogia geral, extraindo dela a noção de pedagogia como campo independente de estudos, que investiga a ação pedagógica triplamente constituída, como ação de governo, ensino e disciplina. Ao justificar a pedagogia como campo independente de estudos, Herbart busca distanciá-la tanto da metafísica como da ciência experimental da época. 0 trabalho reconstrói, na sequência, a crítica de Herbart às duas formas de autoritarismo pedagógico próprias ao governo das crianças, amplamente exercidas em sua época: o castigo físico e a educação livresca. Como defensor do autogoverno pedagógico, ele não pôde, obviamente, aceitar em sua ideia de pedagogia geral qualquer forma de prática educativa que cerceie a liberdade humana. Por fim, a conclusão do ensaio apresenta a atualidade do pensamento de Herbart em relação a três aspectos: autogoverno pedagógico, estatuto da pedagogia e papel do educador (professor) como diretor intelectual. Não se trata aqui de querer transpor simplesmente os ideais pedagógicos desse autor do século XIX para o momento presente, mas sim de buscar nele inspiração conceitual para entender a atualidade em que vivemos e a nós mesmos, enquanto sujeitos que compreendemos tal atualidade.

\section{Palavras-chave}

Herbart - Pedagogia - Autogoverno - Educador - Educando.

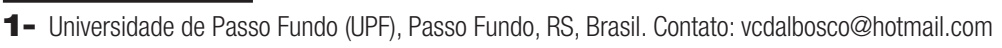




\section{An unconventional reading of Johann Friedrich Herbart: Pedagogical self-government and the active position of the learner}

\section{Abstract}

This essay addresses the work General Pedagogy, published by German pedagogue Johann Friedrich Herbart in 1806. Although Herbart influenced authors such as John Dewey and Jean Piaget, he is considered until today a defender of traditional pedagogy, focusing on the content and authoritarian directing role of the educator. In order to demystify this idea, this essay briefly exposes the architecture of General Pedagogy, drawing from it the notion of Pedagogy as an independent field of study, which investigates the three-fold pedagogical action as that of government, of teaching and of discipline. By justifying Pedagogy as an independent field of study, Herbart seeks to distance it from both metaphysics and experimental science of his time. The essay then reconstructs Herbart's critique of the two forms of pedagogical authoritarianism in the government of children, which were widely exercised at that moment - physical punishment and bookish education. As a defender of pedagogical self-government, he could not obviously accept, in his idea of general Pedagogy, any form of educational practice that curtails human freedom. Finally, it is presented the topicality of Herbart's thought in relation to three aspects: pedagogical self-government, the statute of Pedagogy and the role of the educator (teacher) as an intellectual director. This is not a matter of simply transposing the pedagogical ideals of this nineteenth-century author into the present. It is rather about seeking conceptual inspiration in his work in order to understand the time we live in and ourselves as subjects that understand such time.

\section{Keywords}

Herbart - Pedagogy - Self-government - Educator - Student.

\section{Introdução}

Johann Fredrich Herbart (1776-1841) passou convencionalmente para a história da pedagogia como pedagogo conservador, que teria menosprezado, em nome da defesa intransigente dos conteúdos e do papel diretivo do professor, a posição ativa do aluno no processo ensino-aprendizagem. Esta leitura estandardizada de seu pensamento é solidificada pelas diferentes reformas pedagógicas europeias do final do século XIX e início do século XX. Ao atribuírem centralidade ao papel ativo do aluno no processo de ensino e aprendizagem, elas tendem a enfraquecer o papel diretivo do professor e, por conseguinte, dos teóricos educacionais que, como Herbart, destacam a figura de proa do professor como diretor intelectual da formação do aluno (BENNER; 
BRÜGGEN, 2011, p. 245-278). De outra parte, no dominio da pedagogia brasileira, José Carlos Libâneo confırma a interpretação de Herbart como teórico das matérias de estudo, ao apresentar e não contestar a leitura que Dewey faz do pedagogo alemão (LIBÂNEO, 2002, p. 166).

Contudo, é surpreendente que essa imagem estandardizada de Herbart como convicto defensor das matérias de ensino e do professor como diretor intelectual do processo pedagógico também é sustentada por círculos acadêmicos internacionais atuais, com reconhecida reputação investigativa. 0 segundo Simpósio da Sociedade Internacional Herbart, ocorrido na Bélgica em 2005, teve como tema geral o confronto entre o pensamento pedagógico de Johann F. Herbart e John Dewey.

No referido simpósio, Joop W. A. Berding proferiu a conferência War John Dewey ein (Neo)Herbatianer? Die Debatte zwischen der "alten" und der "neuen” Erziehung (Foi John Dewey um neoherbartiano? 0 debate entre a "nova" e a "velha" educação). Berding inclui, nessa conferência, não só os neoherbartianos, mas também, em certa medida, o próprio Herbart na velha pedagogia, segundo a qual o professor é o centro do processo de ensino e aprendizagem e o espaço da sala de aula é locus da aprendizagem de conteúdos (BERDING, 2014, p. 7-18).

0 debate acadêmico a respeito da figura pedagógica de Herbart reúne questões educacionais relevantes que mostram a atualidade de seu pensamento não só para o contexto pedagógico europeu e americano, mas também para a situação educacional brasileira. A defesa herbartiana do autogoverno pedagógico, da pedagogia como campo independente de estudos e do papel de direção intelectual do educador tornam-se fontes de inspiração para pensar problemas cruciais da educação brasileira atual. Entre tais problemas destacam-se as diferentes formas de servidão ou heteronomia assumidas pelas práticas pedagógicas escolares e a centralidade indevida atribuída ao educando em nome da compreensão equivocada das metodologias ativas.

Contrapondo-se à interpretação estandardizada acima resumida de Herbart, busco apresentá-lo, neste ensaio, como precursor moderno dos métodos ativos, sem que com isso tenha destituído a autoridade legítima do educador, como diretor intelectual, do processo pedagógico. Ou seja, Herbart coloca o educando em posição ativa, mantendo a centralidade formadora do educador. Minha hipótese é a de que ele consegue fazer isso por duas razões: primeiro, porque justifica a independência da pedagogia como campo de estudos; segundo, porque coloca o autogoverno como categoria fundante da própria Pedagogia.

Busco investigar em três momentos a problemática acima anunciada. No primeiro, refiro brevemente à arquitetônica da Pedagogia geral, procurando localizar o problema do governo das crianças. Reconstruo, no segundo momento, a crítica herbartiana às diferentes formas de autoritarismo pedagógico, relatando a autocrítica que Herbart faz de sua própria experiência docente inicial. Procuro mostrar, ao mesmo tempo, em que sentido o autogoverno torna-se a categoria pedagógica chave da Pedagogia geral. Por fim, no terceiro momento, procuro justificar três aspectos da atualidade do pensamento pedagógico de Herbart para o cenário educacional brasileiro. 


\section{A arquitetônica da Pedagogia geral}

Johann Friedrich Herbart publicou a Allgemeine Pädagogik, aus dem Zeweck der Erziehung abgeleitet) (Pedagogia geral, derivada da finalidade da educação) em 1806, quando tinha apenas 30 anos de idade. É uma das maiores obras pedagógicas do século XIX, encontrando certamente lugar destacado na História da Pedagogia ocidental. A Pedagogia geral representa a continuidade da tradição mais alta do esclarecimento pedagógico moderno, sendo herdeira das ideias educacionais de John Locke (1632-1704), Jean Jacques Rousseau (1712-1778) e, principalmente, Immanuel Kant (1724-1804), ao qual Herbart sucede em sua cátedra de filosofia na Universidade de Königsberg, cuja cidade, de mesmo nome, localizava-se no lado oriental do Império prussiano. De outra parte, deixou-se influenciar profundamente pelas experiências pedagógicas de Johann Heinrich Pestalozzi (1746-1827), desenvolvidas na Suiça. 0 próprio Herbart fez, nesse mesmo país, mais precisamente em Berna, a partir de janeiro de 1797, suas primeiras experiências pedagógicas, atuando como preceptor na família de Karl Friedrich Steiger (ASMUS, 1968, p. 108ss).

A Pedagogia geral encontra-se dividida em três livros. 0 primeiro intitula-se $A$ finalidade da educação. Sentido geral, o qual comporta dois capítulos, o governo das crianças e a Educação em geral. 0 primeiro livro, que será objeto específico do presente ensaio, é uma propedêutica dos dois livros seguintes cujo propósito é preparar as bases iniciais do autogoverno do educando. É digno de nota, nesse contexto, o fato de Herbart inserir a preparação do autogoverno infantil no âmbito da educação em geral, mostrando, com isso, que a educação infantil não pode ser concebida de maneira desconectada da ideia geral de humanidade. Isso significa dizer, em outros termos, que a boa educação da criança só é alcançada, segundo ele, quando a formação infantil for pensada em estreita relação com a problematização da condição humana e, simultaneamente, com a noção mínima de mundo que dê a ideia de pertença cósmica tanto ao educador como ao educando. Retomarei, logo abaixo, a ideia de educação geral e a exigência que ela põe à própria noção de Pedagogia.

O segundo livro da Pedagogia geral intitula-se $A$ multiplicidade do interesse, sendo constituído por seis capítulos, dos quais destacam-se, prioritariamente, o primeiro, definido como $O$ conceito de multiplicidade e, o quarto, compreendendo o Curso natural da formação do caráter. Nesse segundo livro, Herbart desenvolve dois núcleos centrais de sua teoria pedagógica geral, a saber, a multiplicidade do interesse e a instrução educativa. Certamente foi por esse segundo livro que o autor se tornou mais atrativo para a pedagogia, sendo também tal livro que mais impulsionou o movimento do neoherbartianismo, responsável pela divulgação mundial das ideias do pedagogo alemão. ${ }^{2}$ É nesse segundo livro que Herbart justifica uma de suas teses centrais, a saber, de que toda a instrução precisa ser educativa (erziehender Unterricht), ou seja, que todo o ensino precisa ser formativo.

2- 0 trabalho de Georg Weiss, intitulado Herbart und seine Schule, publicado ainda em 1928, constitui uma referência clássica para compreender o desdobramento posterior do pensamento pedagógico de Herbart e o modo como foi interpretado pelos seus seguidores. Depois de fazer uma exposição geral das principais ideias do referido pedagogo, Weiss trata da escola de Herbart, acentuando autores como Tuiskon Ziller, Karl Volkmar Stoy e Wilhelm Rein (WEISS, 1928). 
Por fim, o terceiro e último livro da Pedagogia geral chama-se Fortaleza do caráter moral. Também está dividido em seis capítulos. Este livro não tem recebido de modo geral a atenção merecida e a disciplina (Zucht), seu conceito central, tem sido mal compreendida pelos críticos de Herbart. Há, claramente, sob determinado aspecto, a influência kantiana na problematização desse conceito. Mas, por outro lado, Herbart distancia-se de Kant na medida em que atribui papel eminentemente positivo à disciplina, como núcleo constitutivo da formação moral do caráter humano. Para que a disciplina possa desempenhar esse papel, ela não pode ser compreendida só nos termos de um poder disciplinador.

Filiando-se à tradição antiga, especialmente estoica, Herbart compreende a disciplina como uma das principais formas de cultivo do espírito humano. Ou seja, não como poder disciplinador, mas como forma genuína de exercício de si, a disciplina possibilita ao ser humano o cultivo de suas disposições ou capacidades intelectuais. Nesse sentido, a melhor tradução para o português do termo alemão Zucht, no contexto da pedagogia herbartiana, deveria ser mesmo governo moral. ${ }^{3}$

Apresentei, até aqui, um resumo abreviado da arquitetônica da Pedagogia geral. Gostaria de destacar, com base nessa arquitetônica geral, dois aspectos que são importantes para compreender a especificidade da formação do autogoverno infantil. 0 primeiro aspecto refere-se à tipologia tripartite da ação pedagógica que cruza a arquitetônica da obra, assegurando a especificidade de cada um dos três livros e permitindo compreendêlos por meio de uma unidade mínima. Esse fio condutor de leitura da referida obra foi desenvolvido pioneiramente por Dietrich Benner, em seu estudo clássico Die pädagogik Herbarts (A pedagogia de Herbart), publicado na Alemanha, no início dos anos noventa do século passado.

A teoria educacional desenvolvida por Herbart ancora-se, segundo Benner (1993), em uma teoria tripartite da ação pedagógica, constituída como ação de governo, ensino e disciplina. Cada um dos três tipos de ação pedagógica tem princípios e finalidades específicas: a ação pedagógica de governo volta-se para o cultivo da impetuosidade selvagem da criança; o ensino como instrução educativa visa à formação do interesse múltiplo e a disciplina tem a meta de formação moral do caráter. Esses três tipos de ação pedagógica radicam-se na ideia de educação geral, a qual, por sua vez, tem, como meta principal, possibilitar a formação múltipla do sujeito educacional. Portanto, é no âmbito dessa teoria tripartite da ação pedagógica que se coloca o problema do governo das crianças e, em sentido mais amplo, a própria ideia de educação infantil.

0 segundo aspecto importante da arquitetônica da Pedagogia geral refere-se à ideia de educação geral e o conceito de pedagogia dela derivado. A ideia de educação geral é importante para se compreender outros conceitos que lhe estão muito próximos, como de instrução, ensino e didática. Colocando-se bem na esteira do pensamento neohumanista da época, ${ }^{4}$ Herbart compreende a educação como desenvolvimento de todas as disposições (capacidades) humanas nas mais diferentes direções.

\footnotetext{
3- Em trabalho recente acerca de John Dewey e Johann F. Herbart, Andrea English (2013) traduziu Zucht para o inglês como moral guidance, ou seja, como governo moral.

4- Para uma interpretação atual da história da educação alemã moderna, incluindo nela o neohumanismo, ver a obra Geschichte der Erziehung (História da educação), sobretudo o capítulo IV, de Heinz-Elmar Tenorth (2010, p. 121-179).
} 
Para que consiga cumprir essa tarefa de formação intelectual múltipla, a educação não pode ser deduzida, como mostra o autor na própria introdução da Pedagogia geral, nem do sistema filosófico especulativo e nem do método científico experimental moderno. Independente da metafísica e da ciência experimental, a educação precisa de uma Pedagogia independente, que possa investigar autonomamente o conteúdo da ação formativa humana. Como afirma Herbart, seria melhor se a Pedagogia "pudesse refletir com base em seus próprios conceitos (einheimischen Begriffe), cultivando pensamento independente" (HERBART, 1965, p. 21). ${ }^{5}$

Ora, a Pedagogia geral é justamente o esforço de justificar a pedagogia autônoma enquanto estudo da tipologia triparte da ação pedagógica. Nesse sentido, como estudo do governo das crianças, ela torna-se também educação infantil, investigando a condição do ser criança e as próprias condições do ensino e aprendizagem tanto do adulto como da criança. Volto-me para este tema na exposição do próximo tópico.

\section{O problema do governo autoritário das crianças: necessidade do autogoverno}

Se o núcleo da Pedagogia autônoma é a investigação das disposições (capacidades) humanas em suas diferentes direções, o governo das crianças precisa se atentar para isso. Herbart torna-se consciente, ao se deixar ancorar na boa tradição pedagógica, a respeito do fato de que tanto as disposições como suas diferentes direções não permanecem as mesmas ao longo da vida do ser humano. A postura de identificar (perceber) as disposições, como elas aparecem e que direções assumem ou devem assumir diz respeito à questão de governo que se entrelaça intimamente com a formação e o domínio da vontade humana. Portanto, no âmbito da formação humana, como governar as disposições deixando-se orientador pelo domínio ético da vontade é, na perspectiva de Herbart, uma questão educacional de primeira grandeza. A ação pedagógica de governo é um primeiro enfrentamento, no âmbito específico da relação entre educador e educando - o âmbito da educação infantil - dessa questão educacional mais ampla.

Há um aspecto importante da noção de governo que é própria aos séculos anteriores e que deságua na Pedagogia geral. Refiro-me ao estatuto antropológico que lhe é inerente. A noção de governo tem, na atualidade, um sentido institucional forte, referindo-se quase exclusivamente ao poder do Estado e aos sistemas e partidos políticos. Nesse contexto, a noção de governo das crianças caiu em desuso, desaparecendo também o significado que lhe era intrínseco na época de Herbart e que delimitava o âmbito ético e pedagógico da relação com as crianças. Por isso, antes do sentido exclusivamente político, vinculado ao sistema de governo, a própria noção de governo tinha um estatuto antropológico claro, relacionado diretamente ao poder de conhecer e comandar as disposições humanas. Mais precisamente, trata-se da clássica questão ético-político do governo dos outros alicerçado

5- Em ensaio recente, Klaus Prange problematiza as dificuldades relacionadas à exigência posta por Herbart à pedagogia de elaborar seus conceitos próprios. Ao analisar com cuidado alguns conceitos centrais da Pedagogia geral, como governo, ensino e disciplina, logo se percebe, segundo Prange (2014, p. 16), que Herbart os deriva de áreas de conhecimento vizinhas à pedagogia, as quais se encontravam em gestão na ápoca, como a teoria da evolução e própria pesquisa do cérebro. 
no bom governo de si mesmo. Herbart traduz essa questão para o âmbito pedagógico, referindo-se ao modo como o adulto exerce sua autoridade em relação à criança.

Na perspectiva pedagógica do desenvolvimento humano mais amplo, a criança não tem a mesma condição educacional que o adolescente, jovem, adulto ou velho. Pode até existir um contínuo entre os diferentes momentos da vida humana, mas as disposições assumem formas específicas em cada um deles, sem excluir também o fato de que algumas de tais disposições podem, inclusive, manter-se em silêncio. A descoberta e o desenvolvimento adequado das disposições estão intrinsecamente vinculados à formação múltipla de cada ser humano, nos diferentes momentos de sua vida.

Como é na fase inicial da vida humana, principalmente na infância e adolescência, que tais disposições se afloram, é justamente aí que o sentido próprio de educação se torna mais intenso. Conhecer como as disposições humanas se apresentam ao mundo infantil e que direções assumem ou podem assumir é um fator decisivo para a definição da ação pedagógica de governo, delimitando também suas tarefas e procedimentos. Ora, é isso que está referido globalmente ao que Herbart compreende como governo das crianças.

Contudo, ao pensar o governo das crianças, Herbart não compreende o desenvolvimento humano e, especificamente, a infância nos termos do desenvolvimento cognitivo determinado pelo tempo cronológico vinculado à faixa etária do educando. Claro, ele tem presente que é preciso pensar formas específicas de ensino e aprendizagem para orientar a relação pedagógica entre o educador (jovem ou adulto) e o educando (criança). Tem presente também que não se deve antecipar à criança o conteúdo que está fora do alcance de sua capacidade de compreensão. ${ }^{6}$

Como trata no segundo livro da Pedagogia geral, o princípio pedagógico básico de sua instrução educativa é o de que o ensino precisa tornar-se interessante ao educando. Mas, o mais importante é que a educação na infância precisa preparar a inserção do sujeito educacional no mundo, compreendido como natureza e sociedade orientadas por uma ordem ética maior, a qual tem na formação múltipla sua base de sustentação. Ou seja, a educação infantil precisa ser pensada com referência às finalidades da educação geral. Por isso que Herbart considera como decisivo, do ponto de vista arquitetônico de sua ideia de educação, pensar o vínculo da ação pedagógica de governo com os outros dois tipos de ações, o ensino e a disciplina, pois é a relação entre esta tipologia tripartite que dá origem à ideia de formação múltipla.

A noção de governo das crianças, quando compreendida no sentido educacional próprio ao século XIX, refere-se ao exercício inquestionável da autoridade adulta sobre a criança. Esse exercício assume diferentes formas, sendo a forma autoritária a que dominava as práticas educativas da época. Como se apresentava a forma autoritária na prática educativa diária entre pais e filhos, preceptor e seus educandos e, no ambiente educacional escolar, entre professor e alunos?

0 castigo físico era a forma mais severa e humilhante. A longa tradição do esclarecimento pedagógico moderno já havia criticado duramente os efeitos destrutivos

6- Herbart herda claramente este tema da pedagogia iluminista do século XVIII, especialmente do pensamento de Rousseau. Ocupei-me desse problema em Rousseau, principalmente na educação da primeira infância, em meu livro Educação natural em Rousseau. Das necessidades da criança e dos cuidados do adulto (DALBOSCO, 2011). 
que o castigo exercia na formação da identidade infantil. Nesse contexto, cabe fazer breve menção a dois antecessores de Herbart, John Locke (2003), na Inglaterra do século XVII, e Jean-Jacques Rousseau (1999), na França do século XVIII. A referência a esses dois autores é importante, porque cada um lutou intelectualmente, ao seu próprio modo e no século ao qual pertence, contra as diferentes formas de servidão humana, sobretudo, àquela que se manifesta na maneira mais perversa da relação autoritária do adulto sobre a criança, por meio dos castigos físicos.

John Locke e Jean-Jacques Rousseau são, na modernidade, pioneiros da defesa do autogoverno infantil e, por isso, estão conscientes de que a formação voltada ao exercício da liberdade precisa negar a opressão exercida por meio do castigo físico. Como pioneiros do autogoverno infantil, são precursores legítimos da ideia herbartiana de que a criança, devidamente governada pelo adulto, alcança progressivamente a capacidade de dirigir-se a si mesma.

A educação livresca representava a outra forma autoritária exercida pelo educador sobre o educando. Se não se equivalia aos efeitos destrutivos do castigo físico, se constituía igualmente como efeito inibidor da iniciativa própria e da capacidade inventiva do educando. 0 livro, na tradição educacional escolar, tornou-se o símbolo do poder exercido pelo educador sobre o educando. Uma vez que o ensino tradicional primava pelo conhecimento disciplinar, ou seja, o ensino baseado nas disciplinas, o manual de ensino tornou-se então o coração do plano de ensino. 0 espírito educacional escolar, do século XIX, como já o era em séculos anteriores, baseava-se na ideia de que só se poderia ensinar de maneira eficiente com base no manual.

Nesse sentido, o aluno deveria aprender memorizando o que está no manual, com o auxílio verbal enérgico e decidido do professor. Isso valia para todos os educandos, independentemente da idade e especificidade de suas disposições. Mesmo grandes educadores, com mente fértil, capacidade inventiva e recursos pedagógicos variados, deveriam seguir indistintamente o manual de ensino. Exemplo paradigmático é a atividade docente de Immanuel Kant, na Universidade de Königsberg. Ele tinha de orientar-se obrigatoriamente pelo manual de ensino em todas as diferentes disciplinas ministradas, como geografia, história e pedagogia, além da filosofia, embora tal exigência não o impediu de fazer extensas notas no próprio manual e de variar seus recursos pedagógicos. Também Herbart, quando sucedeu a Kant na cátedra da mesma Universidade, teve de continuar ensinando com base no manual. Mas também como Kant, fez extensas notas aos manuais por ele adotado.

0 problema maior talvez não residisse no conteúdo em si do manual de ensino, mas no modo como era usado, acentuando o sentido autoritário do governo da criança. Inserindo-se no procedimento pedagógico mais amplo da relação transmissãomemorização, o uso do manual tornava o ensino maçante e sem sentido para o educando. 0 que valia para o uso do manual repetia-se também com o estudo dos textos clássicos e, principalmente, com o estudo das línguas clássicas, como o grego e o latim. 0 modo como tal estudo era feito coibia a criatividade do aluno, fazendo desaparecer a vivacidade e o poder transformador inerente aos próprios clássicos. Herbart não escapou, em sua atuação docente inicial, da armadilha de tomar como um dado inquestionável a educação livresca. 
Ele mesmo, no início de sua atividade pedagógica, primou pelo espírito filológico em detrimento do espírito pedagógico.

Herbart volta-se para esse problema em uma passagem da Pedagogia geral, localizada ainda na introdução da referida obra, na qual ele faz a autocrítica de sua própria prática pedagógica. A questão de fundo é como o ensino pode tornar-se interessante ao educando e qual seria o melhor perfil do educador para fazê-lo. Depois de reconhecer textualmente a importância da Odisséia de Homero, afırmando que deve a ela "uma das experiências mais agradáveis de sua vida" e seu próprio "amor pela educação", o autor confessa no que errou em sua atividade inicial de pedagogo. Assim afirma ele:

Equivoquei-me pelo fato de concentrar-me excessivamente à rotina escolar e, ao exigir uma análise gramatical rigorosa, ensinar por meio de uma repetição incansável somente as características principais e seguras da reflexão; em vez de exigir tal ensino à criança através de perguntas interessantes (HERBART, 1965, p. 27, grifos no original). ${ }^{7}$

Na sequência da passagem, Herbart continua analisando a origem de seu erro como professor, localizando-o na falta de conhecimento histórico e mitológico. Deixa a entender, desse modo, que para despertar o interessante em seus educandos, deveria ter bom domínio de conteúdo, embora isso ainda não fosse suficiente. 0 reconhecimento público desse erro mostra seu duplo posicionamento pedagógico: como crítica à pedagogia tradicional da época e, ao mesmo tempo, como delineamento de aspectos pedagógicos vitais de sua própria ideia de educação geral. Esse duplo posicionamento está ancorado na autocrítica segundo a qual o pedagogo iniciante faz de sua atividade pedagógica.

0 que está em jogo aqui, nessa passagem, não é obviamente a recusa do diálogo da pedagogia com a tradição cultural passada, pois o esforço de tal diálogo fica claro na medida em que Herbart admite o valor da Odisséia na sua formação, despertando-lhe o amor pela educação. Se o diálogo com a tradição clássica é indispensável à formação múltipla do sujeito educacional, então o problema é o modo como tal diálogo é realizado. Quando a ênfase é apenas filológica, limitando-se à análise gramatical, como faziam tanto a educação tradicional quanto o próprio pedagogo iniciante Herbart, então os estudos dos clássicos antigos, como Homero, não possuem nenhum sentido para os educandos. Ou seja, o simples exercício filológico é incapaz de tornar interessante o estudo dos clássicos e o significado que eles carregam para que o educando possa pensar em si mesmo e na atualidade em que vive. Desse modo, a potencialidade humana e formadora dos textos clássicos permanece simplesmente oculta aos interesses do educando.

Como despertar então no educando a potencialidade formativa inerente ao clássico? Para o filósofo pedagogo Herbart ficou claro, depois da experiência pedagógica mais amadurecida, que o espírito filológico precisava ser completado pelo espírito pedagógico. $\mathrm{Na}$ verdade, no início do processo educativo, quanto menos filologia (análise gramatical repetida) e mais pedagogia, ou seja, exercício vivo movido pela pergunta, melhor o educando

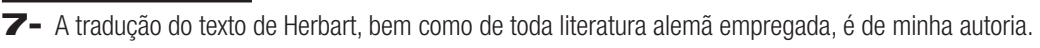


irá associar o conteúdo dos clássicos ao seu círculo de pensamentos (Gedankenkreis). ${ }^{8}$ Não é pela mera repetição de conteúdo, mas sim pelo exercício inquiridor, movido pelo diálogo aberto entre educador e educando, que o ensino se torna interessante. Portanto, a autocrítica de Herbart tem como pano de fundo seu esforço para se distanciar do modo estático e cansativo do ensino da época, expressando sua busca por outro tipo de ensino, baseado na formação múltipla.

Contudo, há ainda outro aspecto da passagem acima que merece ser comentado. Tratase do valor da literatura clássica para a formação múltipla do sujeito educacional. Tudo levaria a crer que a erudição e os estudos linguísticos trariam prejuízo ao fortalecimento do corpo e ao refinamento dos sentidos, restringindo inclusive a "jovialidade social" (HERBART, 1965, p. 24). A objeção habitual da época contra o estudo dos clássicos é que ele (o estudo) tirava o educando do que lhe é mais próximo, de sua vida presente e de suas preocupações atuais, remetendo-o para um passado distante, que não lhe dizia mais respeito. Herbart põe em questão o significado do que é "aquilo que está próximo", mostrando que o mesmo não pode ser simplesmente identificado com a "proximidade sensivel".

Desse modo, quando o problema é remetido para além dos objetos físicos e se consideram o ser humano e as condições humanas, então o que está próximo assume outro significado. Não se trata de simplificar a narrativa e, sobretudo, a leitura do texto clássico, mas sim de extrair dele o "aspecto mais forte e mais puro da grandeza humana, porque o jovem [educando] é tão capaz como nós de distinguir o vulgar e superficial do que é solene" (HERBART, 1965, p. 26). A passagem deixa a entender que o texto clássico, quando é apropriado de maneira adequada, conduz o educando a pensar os problemas que tocam o fundo de sua existência, colocando-o acima das futilidades da vida cotidiana.

Portanto, não se deve recusar o estudo dos clássicos, porque eles supostamente distanciariam o educando das preocupações urgentes de seu momento presente. Mas também não se deveria, ao introduzi-lo na formação do educando, simplesmente reduzilo ao círculo de pensamentos do próprio educando. 0 papel da leitura dos clássicos na formação do educando - e aí é que se insere o significado pedagógico do relato de Herbart sobre sua experiência formativa pessoal com a Odisséia de Homero, serve justamente para ampliar a experiência de mundo e o convívio social do educando. Tal experiência formativa pode ser feita inclusive já com a própria criança, desde que, como alertou o autor acima, o espírito pedagógico predomine sobre os simples exercícios de repetição gramatical. Ora, um dos princípios do ensino educativo é não trabalhar com muito material e nem deixar as coisas fragmentadas, sem ligação entre si.

Compete ao educador, nesse contexto, movido por tal princípio, incentivar o educando a extrair dos grandes personagens dos textos clássicos os traços de personalidade que possam servir de modelo para a formação do próprio caráter, mas sem impô-los ao

8- Embora central, círculo de pensamentos é um dos conceitos mais difíceis da Pedagogia geral. Segundo Thomas Rucker, o "círculo de pensamentos é o processo no qual o ser humano toma reflexivamente a si mesmo e o mundo, desenvolvendo regras de orientação" (RUCKER, 2014, p. 25). 
círculo de pensamentos do educando. ${ }^{9}$ Como reconhece Herbart, tudo depende do tipo de orientação que se dá à leitura do texto clássico. Se a mesma for feita de maneira livre e aberta, certamente provocará ao educando a reflexão sobre a importância de alcançar o seu autodomínio (autogoverno). Ao se deixar inspirar pelas personagens dos textos clássicos antigos, cuja Odisséia é o exemplo paradigmático, o educando, mediado pela orientação do educador, reinventa a própria personagem, ou seja, forma o próprio si mesmo (Selbst).

Depois desse breve relato acerca da autocrítica herbartiana, retorno ao ponto anterior. Era ainda muito comum, no século XIX, a concepção e o exercício autoritários de governo do educador sobre o educando. Tratava-se de um contexto social e político marcado fortemente pelo princípio de autoridade inerente ao poder da nobreza. A sociedade de estamentos tinha papéis sociais definidos por nascimento: o filho do nobre nascia com condição infinitamente superiores ao filho do servo, o qual jamais poderia chegar ele próprio a ser um nobre.

A naturalização da superioridade tornava inquestionável a própria autoridade do nobre em relação ao servo. Tal superioridade assumia conteúdo autoritário, porque implicava obediência cega e submissão irrestrita: o vassalo deveria se inclinar sempre e irrestritamente ao senhor. Esse sentido autoritário de autoridade transpunha-se imediatamente para as relações entre educador e educando, tornando inquestionável também o poder do adulto sobre a criança. Ora, a forma de superioridade incondicional da autoridade adulta marca solidamente a noção de governo da criança assumida pela educação da época.

Nesse contexto, contra a concepção educacional dominante na época, a Pedagogia geral constitui-se em uma experiência original de pensamento - e aí repousa a grandeza da obra -, na qual severidade e rispidez de procedimentos cedem lugar à amabilidade do afeto. Ou seja, se a meta repousa na busca pelo autogoverno exercido por todos, é na autoridade do amor, e não no controle rigoroso e vigilante, que a ação pedagógica precisa se basear. Este ponto é decisivo para compreender, posteriormente, o papel formativo da disciplina, não como um dispositivo do poder dominador, mas sim como um profundo exercício humano de si sobre si mesmo, visando à capacidade de se dirigir a si mesmo (autogoverno ou governo de si). Por isso que a disciplina tem a ver, nesse contexto, com o governo moral e não com adestramento.

Herbart desenvolve então uma concepção geral de governo, colocando-a na base de seus três tipos estandartes de ação pedagógica. Tal concepção cruza a Pedagogia geral, sendo anunciada textualmente, pela primeira vez, logo no início do primeiro capítulo do livro primeiro. Nesse contexto especificamente pedagógico, a natureza do governo precisa ser pensada de tal modo que possibilite o sujeito educacional "governar a si mesmo" (sich zu regieren) (HERBART, 1965, p. 31).

\footnotetext{
9- Outros autores, além de Herbart, já haviam destacado a importância do estudo de grandes autores e seus feitos para a formação das novas gerações. Rousseau, por exemplo, dedica uma parte significativa do quarto livro do Emílio para tratar do estudo de grandes personagens históricas como condição da boa formação do gosto de seu aluno fictício. Ocupei-me desse tema em meu livro Condição humana e educação do amor próprio em Jean-Jacques Rousseau (DALBOSC0, 2016).
} 
Nesse sentido, bom governo é aquele que conduz ao autogoverno dos envolvidos no processo pedagógico. 0 educador, além de saber governar a si mesmo, precisa conduzir a relação pedagógica de tal maneira que possibilite o autogoverno do próprio educando. De sua parte, o educando precisa se decidir ele próprio pelo autogoverno, o que o leva à independização progressiva em relação ao educador. Governar visando ao autogoverno de si mesmo e dos outros e se deixar governar visando ao próprio autogoverno canaliza um conjunto de conflitos e tensões que marca o processo formativo educacional humano. Herbart parte da convicção pedagógica de que a educação geral ancorada no projeto de formação múltipla capacita da melhor forma possível o sujeito educacional para enfrentar tais conflitos e tensões.

Deste modo, no contexto da pedagogia do século XIX e, especificamente, do pensamento pedagógico de Herbart, a finalidade do autogoverno é posta como principal antídoto contra o autoritarismo das práticas educativas humanas. A capacidade de governar-se a si mesmo (sich zu regieren) torna-se o principal remédio contra a obediência cega e à submissão irrestrita, tendo sentido político de longo alcance, desde que seja precedido pela formação moral. Contudo, a Pedagogia geral não se ocupa em explicitar os alcances políticos do autogoverno, mas sim em esclarecer o conteúdo da formação moral, desdobrando-o na tipologia tripartite da ação pedagógica.

Sob este aspecto, a Pedagogia geral, enquanto programa de formação moral é uma propedêutica indispensável ao sentido político do autogoverno humano. Para Herbart, assim como para boa parte dos iluministas modernos, não poderia haver um sentido legítimo de política como vivência pública e transparente de iguais entre iguais, sem a sólida formação moral. Pensavam assim, porque viam na moralidade das ações humanas o principal antídoto contra a corrupção humana e social.

Com a exposição desenvolvida até aqui é possível perceber a centralidade da noção de autogoverno como categoria estruturante da Pedagogia geral. Tal obra volta-se contra as práticas pedagógicas autoritárias da época, ancoradas no castigo físico e na relação vertical entre professor e aluno, assegurada pela imposição do manual de ensino. Como o problema do autogoverno vincula-se de maneira mais sistemática com a arquitetônica da Pedagogia geral? Mais precisamente, de que modo tal problema se deixa justificar na relação pedagógica entre educador e educando?

A Pedagogia geral busca o difícil caminho intermediário, procurando evitar os dois extremos, ou seja, tanto o autoritarismo como o espontaneísmo pedagógico. Ela consegue fazê-lo em parte porque sua noção de pedagogia permite colocar a relação entre educador e educando além desses dois extremos. Antes de tudo, cabe lembrar, com o exposto acima, que Herbart concebe a pedagogia como um campo independente de estudos, atribuindo à ação pedagógica, em sua dimensão tripartite (governo, ensino e disciplina), o núcleo de seus conceitos. Mas em que sentido a ação pedagógica evita que a educação escorregue em um dos dois extremos acima referidos, ou seja, no autoritarismo ou no espontaneísmo?

Nesse contexto, faz-se necessário esclarecer a própria noção de ação pedagógica. Por ação entende Herbart a atividade do sujeito que abarca uma dupla dimensão, inseparável entre si, a sensitivo emocional e a reflexiva racional. Sem a capacidade de sentir e experimentar, o sujeito não consegue manter vínculo com o mundo que o cerca, nem consigo mesmo. Contudo, sem a capacidade reflexiva, o sujeito não consegue elaborar 
o que experimenta por meio dos sentidos. Ora, a pedagogia como estudo independente precisa dar conta dessa dupla dimensão constitutiva da ação do sujeito e mostrar como essa dimensão torna-se possível pedagogicamente. Ou seja, compete à Pedagogia desenvolver as condições educativas que possibilitem ao educando elaborar experiências cada vez mais complexas.

Nesse contexto, Herbart lança mão de dois princípios pedagógicos fundamentais: primeiro, é preciso assegurar ao educando a possibilidade de fazer suas próprias experiências; segundo, cabe ao educador o papel orientador, como diretor intelectual. Tal papel assumido pelo educador é condição indispensável para que o educando possa elaborar intelectualmente suas experiências.

A possibilidade de o aluno fazer suas experiências vem representada, na Pedagogia geral, pela noção de interesse, que é a categoria chave do segundo livro e, certamente, uma das categorias pedagógicas mais importantes da referida obra. É pela noção de interesse que o educador chega ao mundo do educando, fazendo com que o conteúdo se torne interessante ao aluno. Tornar a aula interessante é, para Herbart, um dos principais desafios pedagógicos. 0 professor consegue fazê-lo tomando como ponto de partida o convívio humano e a experiência de mundo do aluno. Contudo, ambos, convívio humano e experiência de mundo, se são o ponto de partida, não devem ser o ponto de chegada do processo pedagógico.

Daí que se justifica a crítica que Herbart faz, ainda na introdução da Pedagogia geral, ao "experimentalismo pedagógico", quando afirma que "de uma experiência nada se aprende" (HERBART, 1965, p. 20). Ao afirmar isso, ele tem em mente somente aquele tipo de experiência que é constituído por observações dispersas, que o sujeito educacional é incapaz de conectá-las entre si. Sendo assim, é papel da pedagogia, como estudo independente, proporcionar aos envolvidos no processo pedagógico, a elaboração intelectual da experiência. ${ }^{10}$ Mas a pedagogia só pode fazê-lo se for estudo reflexivo e não simplesmente ciência de observações sensíveis e aleatórias.

Se o princípio pedagógico central de construir a própria experiência implica a possibilidade da elaboração intelectual, salta aos olhos, imediatamente, o papel de direção intelectual que o educador (professor) exerce em relação ao educando (aluno). Certamente, o educador é o parceiro incansável do educando, conhecendo e respeitando seus sentimentos, mas sem vacilar no que se refere ao seu papel intelectual de contribuir para que o educando alcance níveis cada vez mais elevados de elaboração da própria experiência.

Herbart pensa esse desafio formativo, no âmbito da Pedagogia geral, por meio da tensão entre Vertiefung (aprofundamento) e Besinnung (reflexão), como dois polos que constituem metodologicamente o procedimento do ensino. Propiciar que o aluno faça os próprios aprofundamentos e que passe deles à reflexão é um dos principais desafios metodológicos do ensino. Desse modo, aprofundamento e reflexão estão na base da formação intelectual múltipla, pois estimulam professor e aluno a descobrirem suas disposições (capacidades), desenvolvendo-as nas mais diferentes direções.

10- Não é muito difícil de perceber, sob este aspecto, o quanto Herbart antecipa o pensamento pedagógico de John Dewey. A respeito disso, ver o livro de Andrea English, já referido anteriormente. 


\section{Possível atualidade da Pedagogia geral}

Estamos hoje a mais de dois séculos distantes da publicação da Pedagogia geral. Essa obra reflete, com precisão, o contexto pedagógico europeu do final do século XVIII e início do século XIX, sintetizando o anseio por liberdade e pela busca de formas de relação pedagógica cada vez mais autônomas e menos opressivas. Embora seja uma obra do século XIX, por ser clássica, atravessa o tempo e mostra sua atualidade, inclusive, não só para o contexto pedagógico europeu, senão também ao contexto latino-americano e, especificamente, brasileiro atual. Nesse sentido, gostaria de referir, nesta terceira e última seção do ensaio, sua atualidade para o atual contexto educacional brasileiro sob três aspectos.

0 primeiro deles refere-se ao problema do autogoverno. Como já fora mostrado, entre outros autores, por Dietrich Benner (1993), um dos motivos intelectuais e políticos centrais da Pedagogia geral é a crítica à sociedade de estamentos própria ao feudalismo e, com ela, ao servilismo que lhe era inerente. A ideia do autogoverno consiste justamente, por um lado, na oposição irrestrita a qualquer tipo de servidão e, por outro, na justificativa da liberdade como possibilidade ontológica inerente à condição humana. Se todos têm direito à liberdade, não se justifica nenhum tipo de servidão. Contudo, se a liberdade é uma possibilidade ontológica, ela precisa ser conquistada pedagogicamente, ou seja, como resultado de um longo e ininterrupto processo formativo. Como a condição humana infantil é mais frágil e vulnerável, pois a criança deixa-se mover facilmente por sua impetuosidade selvagem, o problema do autogoverno assume aí toda sua profundidade e, ao mesmo tempo, sua paradoxalidade: a criança que ainda não pode exercer o domínio sobre si mesma precisa ser dirigida pelo adulto de tal modo que possa conquistar progressivamente seu autodomínio.

Se a sociedade brasileira não é mais uma sociedade de estamentos no sentido medieval, não deixa de promover em seu seio diferentes formas modernas e atualizadas de servidão. 0 fato de não ser mais feudal, mas sim capitalista, não significa dizer que eliminou a desigualdade social e promoveu satisfatoriamente a justiça social entre seus membros. Preserva ainda, talvez com mais intensidade, nas relações pessoais e institucionais, formas cada vez mais sutis de servidão, tornando, em tempos de sociedade digital, seres humanos servos uns dos outros e de si mesmos. Portanto, enquanto existir qualquer forma de servidão, quer seja antiga ou moderna, a humanidade continua precisando de uma pedagogia do autogoverno. Nesse contexto, a pedagogia herbartiana não tem, obviamente, todas as respostas, mas serve ainda como fonte de inspiração para pensar formas de resistências à servidão atual e, sobretudo, para pensar o delicado e sempre atual problema da educação das novas gerações e, com isso, da relação do adulto com a criança, do professor com o aluno.

0 segundo aspecto diz respeito ao estatuto da pedagogia como campo independente de estudo. Herbart e sua época tinham diante de si o desafio de pensar a formação múltipla e em diferentes direções das novas gerações, visando a atender as exigências existenciais e profissionais postas pela sociedade que começava a se tornar cada vez mais plural e complexa. Sua crença educacional depositava na pedagogia, mas não na metafísica, nem na ciência experimental, a força intelectual capaz dirigir a formação múltipla do educando. 
Para formar o perfil humano múltiplo, fazia-se necessária a amplidão de espírito capaz de vincular organicamente - e não só formalmente - experiência de vida e formação escolar. Como campo de investigação da ação pedagógica, a pedagogia poderia pensar então temas e questões específicas que se apresentavam nos diferentes períodos da formação humana. Desse modo, Herbart atribuiu à noção de ação pedagógica o importante papel de investigar a tensão permanente entre teoria e prática que constitui o processo formativo humano. Ele pôde fazê-lo, como mostrou Günter Buck (1985), em seu clássico estudo Herbarts Grundlegung der Pädagogik (A fundamentação da pedagogia em Herbart), porque tornou a educabilidade (Bildsamkeit) conceito nuclear da pedagogia, justificando sua independência em relação à filosofia e à ciência, ao mesmo tempo em que atribuiu conteúdo empírico à própria noção de ação pedagógica. Sendo assim, a educabilidade está no centro da experiência formativa humana, permitindo pensar o aspecto propriamente formativo da relação entre educador e educando, entre professor e aluno.

Não se trata, obviamente, de fazer renascer tal e qual a crença em uma pedagogia geral e autônoma, ancorada na noção de educabilidade humana, pois com o desenvolvimento de várias ciências auxiliares torna-se cada vez mais clara a importância do diálogo interdisciplinar. Para o enriquecimento conceitual e aumento de sua potencialidade reflexiva, a pedagogia necessita do diálogo permanente com outras áreas do conhecimento humano. Contudo, o diálogo crítico com a ideia herbartiana de pedagogia pode servir como contraponto às diferentes formas contemporâneas de reducionismo da pedagogia, especialmente àquela, como mostrou Gert Biesta (2013), implicada na redução geral da formação humana à noção de aprendizagem, compreendida como domínio de competências e habilidades específicas.

Por fim, o terceiro aspecto compreende a direção intelectual do educador. Como vimos acima, contra as formas de autoritarismo pedagógico que colocavam o educando em uma condição meramente passiva, Herbart faz o pêndulo dobrar-se para o outro lado. Sua insistência na ideia do autogoverno tornou-se indispensável para ressaltar a dimensão ativa do educando no processo pedagógico; isso vem expresso na ideia de que o educando precisa dirigir-se a si mesmo. Consciente da importância pedagógica de se valorizar a experiência do educando, Herbart pode ser considerado, sob este aspecto, como defensor pioneiro da metodologia ativa. Contudo, sua defesa do autogoverno pedagógico não significa o enfraquecimento do papel do educador. Ao contrário, sua crença pedagógica repousa na ideia de que a valorização adequada da experiência do educando só é possível mediante à liderança intelectual do educador.

Nesse sentido, a pedagogia herbartiana mostra sua atualidade crítica justamente no momento em que a pedagogia contemporânea parece ter sucumbido, segundo diagnóstico de Hannah Arendt (1994), à ditadura do educando e do grupo. Criou-se a falsa ilusão pedagógica de que a melhor forma de aprendizado é deixar fazer. Tal ilusão está conduzindo a cultura contemporânea em geral e a cultura escolar em particular para um vazio de experiência intelectual. Precisamos, atualmente - e esta talvez seja a maior exigência educacional contemporânea-, de mais conteúdo e menos atividades. Sob esse aspecto, nunca é demais lembrar que não só Herbart, senão também Jean Piaget e John Dewey, autores aparentemente tão distintos entre si, concebem o agir (a ação) e não o 
simples fazer como categoria pedagógica chave. Ou seja, segundo eles, não é a simples atividade, mas sim a ação (reflexiva) que permite a elaboração intelectual da experiência e, com ela, a própria elevação formativa da condição humana.

\section{Considerações conclusivas}

Contra a posição estandarte que põe Herbert no âmbito da pedagogia tradicional, focada nos conteúdos e no papel diretivo autoritário do educador, procurei apresentá-lo, na primeira seção deste ensaio, como defensor convicto do autogoverno pedagógico. Tornouse importante, para meus propósitos, expor brevemente a arquitetônica da Pedagogia geral, para extrair daí a noção de pedagogia como campo de estudos independente que investiga a ação pedagógica triplamente constituída, como ação de governo, ensino e disciplina.

Reconstruí, na segunda seção, a crítica de Herbart às duas formas de autoritarismo pedagógico próprias ao governo das crianças, amplamente exercidas em sua época: o castigo físico e a educação livresca. Apresentei, no mesmo contexto, sua própria autocrítica em relação ao autoritarismo pedagógico que dominou a experiência pedagógica inicial do jovem Herbart. Por fim, na terceira e última seção, procurei mostrar a atualidade do pensamento pedagógico de Herbart para o contexto educacional brasileiro, considerando três aspectos: o problema do autogoverno, o estatuto da pedagogia e a direção intelectual do educador.

Os três aspectos da pedagogia de Herbart que tomei como referência para pensar problemas educacionais atuais estão profundamente vinculados entre si, pois o ideal do autogoverno como condição indispensável da relação formativa entre educador e educando depende de uma pedagogia autônoma, capaz de dialogar com outras formas de conhecimento humano, sem ter de abrir mão de suas especificidades. Se não é mais possível defender hoje, ao menos não mais nos mesmos termos como o fizera Herbart, a independência da pedagogia, não devemos abrir mão, contudo, de sua importância para pensar o sentido profissional ampliado da formação atual do pedagogo. Isso porque parece ser uma convicção cada vez mais forte de que o bom profissional não se forma só com o domínio de saberes específicos, referentes exclusivamente a sua profissão.

Para dar conta de exigências cada vez maiores postas pela sociedade plural e complexa, o profissional precisa de domínio cultural amplo que possa o colocar em contato com outras perspectivas culturais diferentes da própria cultura, as quais possam lhe auxiliar para romper com os limites inerentes à sua própria cultura. Ora, a insistência da pedagogia herbartiana na formação das múltiplas capacidades humanas, em direções diversas, pode ainda ser útil para ampliar o horizonte de mundo de quem ao formar também se deixa formar, ou seja, ela pode ainda dizer algo tanto para educador como educando. 


\section{Referências}

ARENDT, Hannah. Zwischen vergangenheit und zukunft. München/Zürich: Piper, 1994.

ASMUS, Walter. Herbart, Band I: der Denker. Heidelberg: Quelle \& Meyer, 1968.

BENNER, Dietrich. Die pädagogik Herbarts: eine problemgeschichtliche Einführung in die Systematik neuzeitlicher Pädagogik. Weinheim/München: Juventa-Verlag, 1993.

BENNER, Dietrich; BRÜGGEN, Friedhelm. Geschichte de pädagogik: Vom Beginn der Neuzeit bis zur Gegenwart. Stuttgart: Philipp Reclam, 2011.

BERDING, Joop W. A. War John Dewey ein (Neo)Herbatianer? Die debatte zwischen der 'alten' und der 'neuen' Erziehung. In: PRANGE, Klauss (Hr.). Herbart und Dewey: pädagogische paradigmen im Vergleich. Jena: Garamond Verlag. p. 7-18, 2014. (Edition Paidei).

BIESTA, Gert. Para além da aprendizagem: educação democrática para um futuro humano. Belo Horizonte: Autêntica, 2013.

BUCK, Günter. Herbarts Grundlegung der pädagogik. Heidelberg: Carl Winter - Universitätsverlag, 1985.

DALBOSCO, Claudio Almir. Condição humana e educação do amor próprio em Jean-Jacques Rousseau. São Paulo: Loyola, 2016.

DALBOSCO, Claudio Almir. Educação natural em Rousseau: das necessidades da criança e dos cuidados do adulto. São Paulo: Cortez, 2011.

ENGLISH, Andrea. Discontinuity in learning: Dewey, Herbart, and education as transformation. New York: Cambridge University Press, 2013.

HERBART, Johann. Friedrich. Pädagogische schriften. Zweiter Band: Allgemeine Pädagogik, aus dem Zweck der Erziehung abgeleitet (1806). Herausgegeben von Walter Asmus. Düsseldorf/München: Verlag Helmut Küpper Vormals Georg Bondi, 1965.

LIBÂNEO, José Carlos. Pedagogia e pedagogos, para quê? São Paulo: Cortez, 2002.

LOCKE, John. Some thoughts concerning education. New York: Oxford University Press, 2003.

PRANGE, Klaus. Überlegungen zur operative Begründung der einheimischen Begriffe der Pädagogik. In: CORIAND, Rotraud; SCHOTTE, Alexandra (Hg.). "Einheimische Begriffe" und disziplinentwicklung. Jena: Garamond Verlag. p. 15-22, 2014. (Edition Paideia).

ROUSSEAU, Jean-Jacques. Oeuvres complètes: Emile. Tomo IV. Paris: Gallimard, Bibliothèque de la Plêiade, 1999. 
RUCKER, Thomas. Politische bildung im kontext von Regierung, unterricht und zucht. Journal of Social Science Education, Bielefeld/Hamburg, v. 13, n. 1, p. 22-33, 2014.

TENORTH, Heinz-Elmar. Geschichte der erziehung: einführung in die grundzüge ihrer neuzeitlichen entwicklung. Weinheim/M6unchen: Juventa, 2010.

WEISS, Georg. Herbart und seine schule. München: Verlag Ernst Reinhardt, 1928.

Recebido em: 12.07.2017

Revisões em: 05.04.2018

Aprovado em: 25.04.2018

Claudio Almir Dalbosco é doutor em filosofia pela Universidade de Kassel (Alemanha) e professor titular dos cursos de graduação em Filosofia e Pedagogia e do Programa de Pós-graduação em Educação da Universidade de Passo Fundo (UPF/RS). 